\title{
The Incidence of Dry Eye Disease Related to Long Term Diabetes Mellitus Tip 2
}

\author{
Nora Burda* \\ Ophthalmology Service, Albania
}

Submission: December 14, 2016; Published: January 25, 2017

*Corresponding author: MD Nora Burda, Polyclinic of Specialties Nr. 2, Ophthalmology Service, Tirana, Albania,

Email: nora.burda.md.al@gmail.com

Keywords: Diabetes mellitus; Dry eye; Goblet cell; HbA1c level; Tear meniscus

Abbreviations: DM: Diabetes Mellitus; DES: Dry Eye Syndrome; TUBT: Tear Break Up Time; BVCA: Best Corrected Visual Acuity; SPK:

Superficial Punktate Keratitis; MGD: Meiboimian Gland Dysfunction; MG: Meiboimian Gland

\section{Introduction}

Diabetes is a disease that affects the body's ability to produce or use insulin effectively to control blood sugar (glucose) levels. DM is a chronic metabolic disorder usually genetic $[1,2]$. The global diabetes mellitus evidence predicts that $6.4 \%$ of the world population are affecting 286 million adults in 2010 by 2030 is predicted to increase about $7.6 \%$ affecting about 439 million of adults [2]. People with diabetes frequently develop dry eye syndrome [3]. It is estimated that over $50 \%$ of people with type 2 diabetes have dry eye [4]. Patients will complain of eye irritation, excessive tearing, fatigue, red eye, gritty sensation, increased watering of the eyes, dryness and blurred vision $[5,6]$.

The causes of dry eye are so many, but the main cause is a disturbance of the tear film due to either decreased tear production or excessive evaporation of tears. MGD occurs when the normal function of the MG becomes compromised because of gland blockages that occur over time, resulting in inadequate oil production into the tear [7]. If the MG malfunctions, the lipid layer may be reduced, allowing rapid evaporation of the tear complex [7-9]. Research shows that most cases of dry eye associated with diabetes are caused by insufficient production of tears due to "autonomic neuropathy. The condition is affecting the nerves that control the lacrimal gland secretion damaging the production of tear film that normally produce moisture to keep the eyes well lubricated $[10,11]$. When the transparent and sensitive cornea is no longer adequately lubricated, the cells of the cornea become damaged and free nerve endings are exposed. The exposure of the nerve endings leads towards symptoms of dry eye.
Furthermore, by keeping blood sugar levels as firmly controlled as possible is the first step in preventing dry eye syndrome at diabetes patients. The high blood glucose HbA1c more than $6.4 \%$ lead to autonomic neuropathy affecting the tear gland but also affects the quality of our tears by increasing the amount of glucose in the tears layers and disrupting their normal chemical composition [12,13]. The tear fluid contains water, lipids, mucin, lactoferrin, lysozyme, lipocalin, imunoglobulins, glucose, urea, sodium potassium, lacritin [14].

Three layers are components of tear film: the aqueous layer, the mucus layer and the lipid layer. Also the goblet cells of conjunctiva plays very important role by producing and secreting mucin lubricating the ocular surface [7].

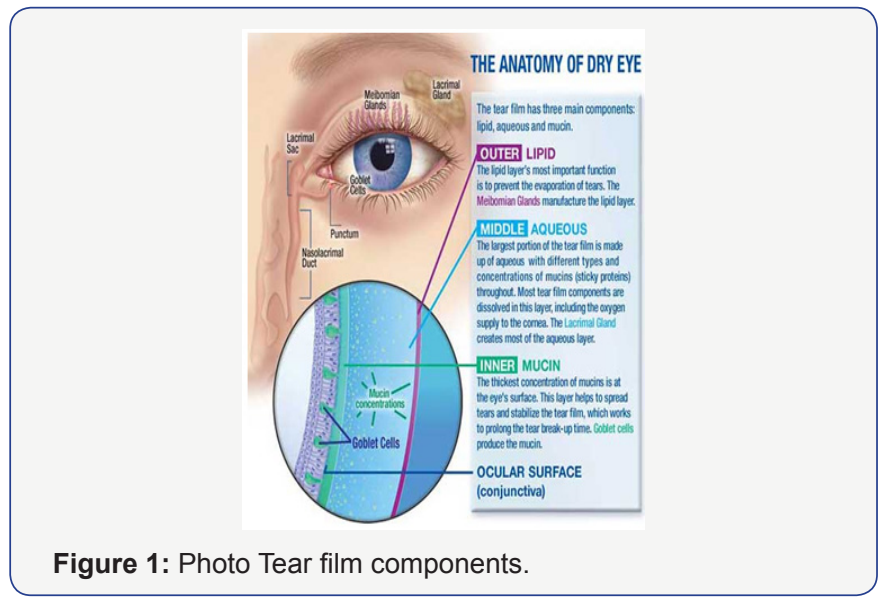


Insufficient tear production and changes in osmolarity promote high concentrations of proteins within the tears inducing apoptosis of surface epithelium and a vicious cycle of increased expression of inflammatory cytokines from ocular surface [7]. The condition gets even worse by apoptosis and decreased mucin production by goblet cells [15] (Figure 1\&2).

\begin{tabular}{|l|c|c|}
\hline HbA1c targets & mmollmol & $\%$ \\
\hline Non-diabetics & $20-41 \mathrm{mmol} / \mathrm{mol}$ & $4 \% \cdot 5.9 \%$ \\
\hline Diabetics & $48 \mathrm{mmol} / \mathrm{mol}$ & $6.5 \%$ \\
\hline $\begin{array}{l}\text { Diabetics at higher risk of } \\
\text { hypoglycemia }\end{array}$ & $59 \mathrm{mmol} / \mathrm{mol}$ & $7.5 \%$ \\
\hline
\end{tabular}

HbA1c levels between $5.7 \%$ and $6.4 \%$ indicate increased risk of diabetes (prediabetes).

Figure 2: Photo HbA1c classification.

\section{Purpose}

The purpose of the study is to prescribe and analyze the correlation of Dry Eye with diabetes related to duration of primary disease.

\section{Methods}

A total number of 98 non selective patients, diagnosed with Diabetes Mellitus Tip II, sent for routine examination from Endocrinologist, underwent ocular examinations. 50 male and 45 female, aged from 42-84 years old.

History of disease, duration of diabetes, age, sex, the level of hemoglobinA1c equal or over than $6.5 \%$ (for the past 3 months) was obtained by reviewing the medical records from the Endocrinology Department and direct patient interview. Visual acuity with correction BVCA, OSDI questionnaire for classification of DES. Slight- lamp examination, tear meniscus at inferior lid margin, tear film break-up time (BUT) test, corneal sensitivity test, Schirmmer Test to evaluate the tear film secretion from the lacrimal gland, Rose Bengal stain test for the conjunctiva goblet cells malfunction, fluoresceine corneal dye test to evaluate the corneal epithelial involvement. Also tear film measurement performing Schirmmer's test in 5 min time to evaluate the amount of tear film production from Lacrimal Gland, cotton-swab test for the corneal sensitivity damage and peripheral neuropathy. Tear film break up time test measurement was performed using fluorescein strips.

Visual acuity was evaluated by using Snellen's chart. Slit lamp (Nidek SL-450) examination was performed with particular attention to lid margin, bulbar and tarsal conjunctiva, cornea and conjunctiva to detect any abnormality of meiboimian Gland Disfunction and also the presence of Superficial Punktate keratitis or any involvement reduction of Golbet cells production. In addition the patient complains of tearing photophobia, red eye, itching, foreign body sensation, increased watering of the eyes, dryness and blurred vision was obtained. The duration of primary disease was recorded and divided in three groups of patients: duration onset of DM -5 years, duration of 5-10 years and more than 10 years of duration (Figure 3-5).

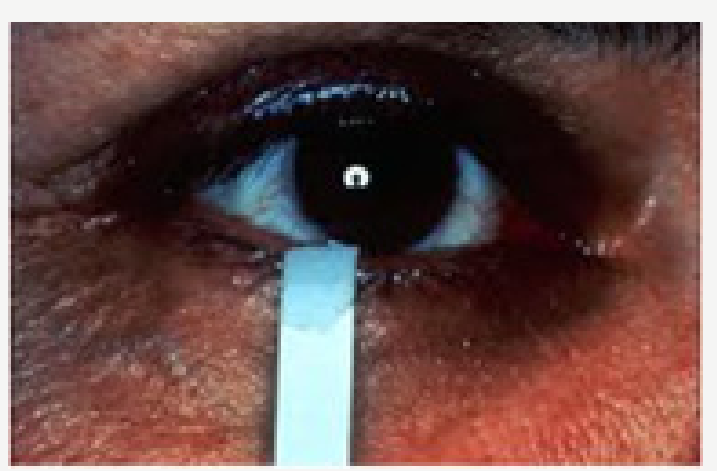

Figure 3: Photo Schirmmer test.

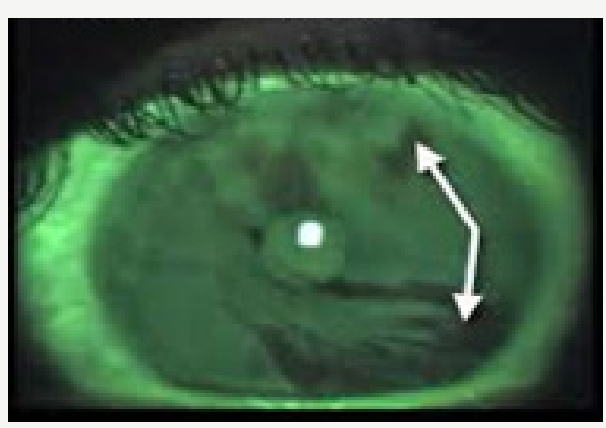

Figure 4: Photo TUBT-break up.



Results

From our research the results are as follows. 64 patients were diagnosed with Dry Eye Syndrome of varying degrees from mild to very severe according to OSDI questionnaire, 28 male / 36 female. The diagnosis was made by having two or more positive tests performed as mentioned above and patient's complaints. In addition, at those subjects diagnosed with DES, 5 patients represent pinpoint corneal dye with fluorosceini (SPK), 8 of them where positive to corneal cotton swab test, 16 of them resulted positive to Schirmer test less than $10 \mathrm{~mm}$ in $5 \mathrm{~min}, 14$ of them was showing TBUT test less than 9 sec, presence of positive tear meniscus was seen in 15 patients, Rose Bengal staining of conjunctiva was detected in 6 patients, MGD was noticed at 12 subjects. Regarding the duration of Diabetes in our study the 
findings where : 21 patients were diagnosed with DM during the period of 5 years of duration, 31 of the patients were diagnosed with DM since 5-10 years ago, 46 of them had Type 2 more than 10 years.

With insight at the group with 5 years of duration there was a low number of patients presenting very mild dry eye at 11 patients, at group with 5-10 years of duration of DM there were about 20 patients presenting mild and severe dry eye, considering that the group included patient with DM more than 10 years of duration; 31 patients were presenting severe to very severe DES (Figure 6\&7).

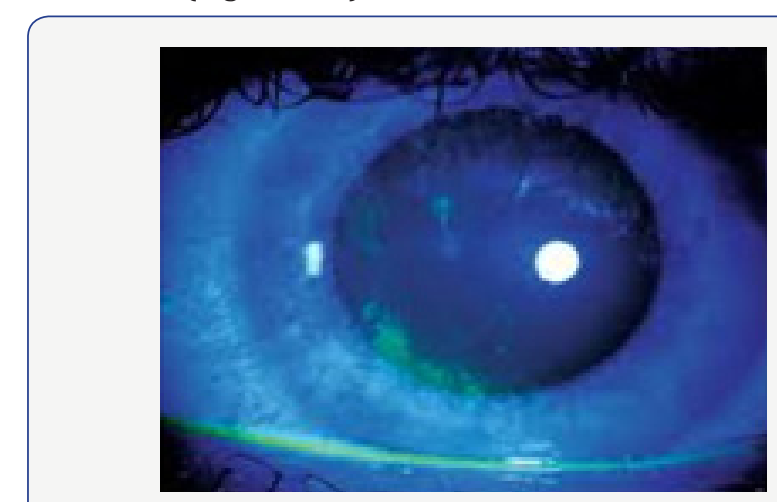

Figure 6: Photo Corneal staining SPK.

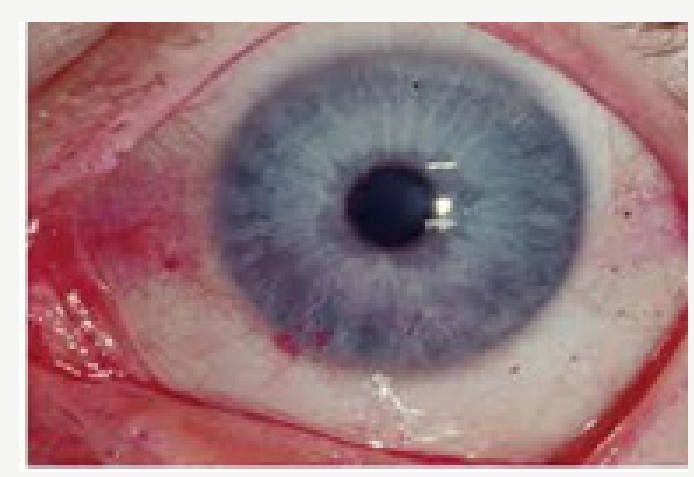

Figure 7: Photo Rose -Bengal staining of conjunctiva.

\section{Conclusion}

This study, the Dry Eye Syndrome showed to have a high correlation with Diabetes Mellitus Tip II (about56.9\%). Prevalence and severity of Dry Eye was significantly higher at patients with longer duration of diabetes (46.9\%)) and poor glycaemic control, less high at the patients with no longer duration of primary disease. Dry Eye seems to be an important contributing factor related to corneal abnormalities by disrupting the normal chemical composition of the tear film layers. In our study we have shown that the Age and Sex seem to not play an important role in this condition. Good glycaemic control is very important and decisive for prevention of the DES.

\section{Discussion}

To conclude, everything depends on blood sugar levels (HbA1c). The higher the attention monitoring the blood sugar level consists in our first step in preventing dry eye syndrome associated with diabetes [12]. More often, the patients are unaware that their blood glucose is out of control, which is fundamental for the treatment at diabetes related to dry eye syndrome [16]. Educating the patients by sharing our knowledge of primary disease DM, the proper treatment, the appropriate monitoring, the diet instructions the exercises and follow up by Endocrinologist is the key to improve the quality of their life style [2] and to reduce the risk for developing DES as much as possible.

Subsequently, it is very important to achieve a good collaboration among physicians to detect early the DM Type 2, to receive the proper management and treatment options for the patient [17]. Compliance of the patients is also a very important factor to learn how to live with diabetes and to present regularly for follow-up. The DM is a chronic disease hence either the DES remain chronic disease as well, for that reason is still very difficult to manage both conditions [15]. New modalities need to be developed though collaborative research and further studies need to be undertaken to treat the DES and the primary disease DM constantly (Figure 8).

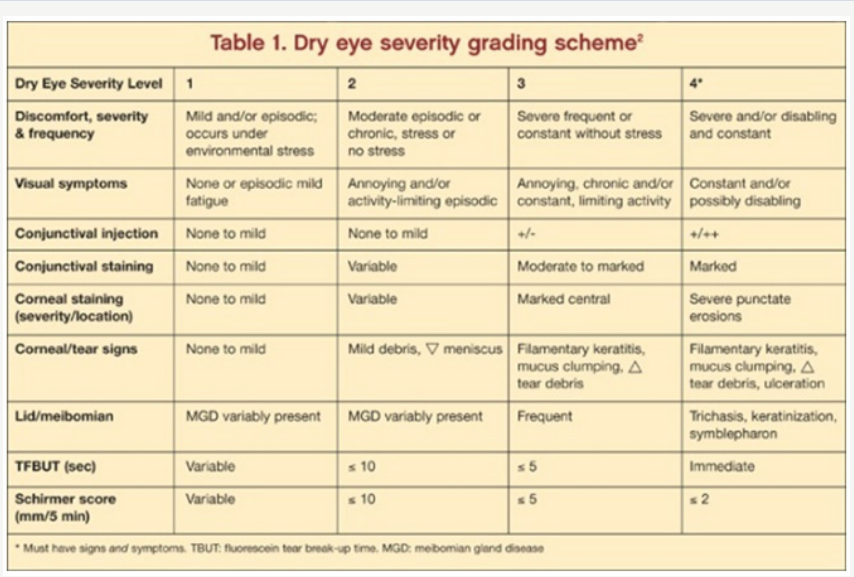

Figure 8: Photo DES Delphi Panel grading scheme. 


\section{References}

1. Anshel J (2010) Prevent diabetes for life. Rev Optom 147(1): 53-59.

2. Cagliero E, Levina EV, Nathan DM (1999) Immediate feedback of HbA1c levels improves glycemic control in type 1 and insulin treated type 2 diabetic patients. Diabetes Care 22(11): 1785-1789.

3. Tumosa N (2008) Eye disease and the older diabetic. Clin Geriatr Med 24(3): 515-527.

4. Manaviat MR, Rashidi M, Afkhami-Ardekani M, Shoja MR (2008) Prevalence of dry eye syndrome and diabetic retinopathy in type 2 diabetic patients. BMC Ophthalmol 2: 8-10.

5. (2013) Dry eye syndrome American. Academy of Ophthalmology Cornea/External Disease Panel, Preferred Practice Patterns Committee. San Francisco, USA, p. 1-44.

6. Gilbard JP (1994) Dry eye disorders. Aajf AD Med Principles and Practice of Ophthalmology-Clinical Practice. Philadelphia, Pa WB Saunders Co, USA, pp. 257- 276.

7. Pflugfelder SC, Tseng SC, Yoshino K, Monroy D, Felix C, et al. (1997) Correlation of goblet cell density and mucosal epithelial membrane mucin expression with rose bengal staining in patients with ocular irritation. Ophthalmology 104(2): 223-223.

8. Tu EY, Rheinstrom S (2008) Dry eye. In: Ophthalmology ( $3^{\text {rd }}$ edn), Yanoff M, Duker JS, (Eds.), Mosby Elsevier: St Louis, USA, pp. 324-329.

9. Seifart U, Strempel I (1994) The dry eye and diabetes mellitus. Ophthalmologe 91(2): 235-239.

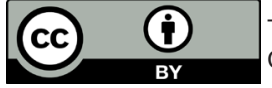

This work is licensed under Creative Commons Attribution 4.0 Licens
10. Alves Mde C, Carvalheira JB, Módulo CM, Rocha EM (2008) Tear film and ocular surface changes in diabetes mellitus. Arq Bras Oftalmol 71(6 Suppl): 96-103.

11. Lockwood A, Hope-Ross M, Chell P (2006) Neurotrophic keratopathy and diabetes mellitus. Eye (Lond) 20(7): 837-839.

12. Delamater AM (2006) Clinical use of hemoglobin A1c to improve diabetes management. Clin Diabetes 24(1): 6-8.

13. (2007) The definition and classification of dry eye disease: report of the Definition and Classification Subcommittee of the International Dry Eye WorkShop. Ocul Surf 5(2): 75-92.

14. Van Setten GB, Tervo T, Viinikka L, Pesonen K, Perheentupa JA, et al. (1991) Ocular disease leads to decreased concentrations of epidermal growth factor in the tear fluid. Curr Eye Res 10(6): 523- 527.

15. Contreras-Ruiz L, Ghosh-Mitra A, Shatos MA, Dartt DA, Masli S (2013) Modulation of conjunctival goblet cell function by inflammation cytokines. Mediators Inflamm 2013: 636812.

16. Walker PM (2007) Visual function in normal compared to patients diagnosed with dry eye as measured by the inter-blink interval visual acuity decay (IVAD) test.

17. Miljanović B, Dana R, Sullivan DA, Schaumberg DA (2007) Impact of dry eye syndrome on vision-related quality of life. Am J Ophthalmol 143(3): 409-415.

\section{Your next submission with Juniper Publishers} will reach you the below assets

- Quality Editorial service

- Swift Peer Review

- Reprints availability

- E-prints Service

- Manuscript Podcast for convenient understanding

- Global attainment for your research

- Manuscript accessibility in different formats

( Pdf, E-pub, Full Text, Audio)

- Unceasing customer service

Track the below URL for one-step submission

https://juniperpublishers.com/online-submission.php 